\title{
¿Qué sentido se atribuyó al zoon politikon

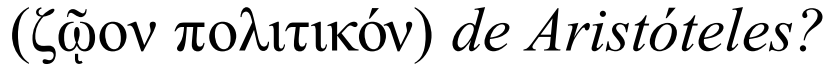 Los comentarios medievales y modernos a la Política
}

\author{
Salvador Rus RuFinO \\ Francisco ARENAS-Dolz ${ }^{1}$
}

Recibido: 29 de octubre de 2012.

Aceptado: 15 de febrero de 2013.

\section{RESUMEN}

Aristóteles caracterizó al ser humano que actúa en la esfera pública como zoon poli-

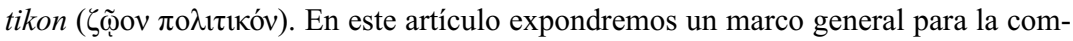
prensión de esta propiedad fundamental del ser humano, viendo cómo se ha entendido de diversas maneras en su desarrollo histórico. Esta situación tiene implicaciones importantes para la teoría política, ya que sugiere que el ser humano está predispuesto a la sociabilidad: el hombre por naturaleza es un animal social que vive con otros y sólo puede alcanzar la justicia y el bien común a través del diálogo y la deliberación, puesto que, como el mismo Aristóteles señala, es el único zoon logon ekon

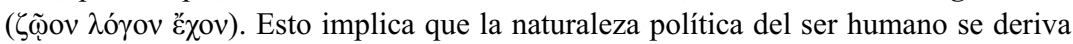
de su naturaleza retórica.

\section{PALABRAS CLAVE}

Aristóteles, retórica, teoría política, zoon politikon.

${ }^{1}$ Este estudio se inserta en los Proyectos de Investigación Científica y Desarrollo Tecnológico FFI2010-21639-C02-01 y FFI2012-35734, financiados por el Ministerio de Economía y Competitividad del Gobierno de España y con Fondos FEDER de la Unión Europea. 


\begin{abstract}
Aristotle held that human beings acting in the public sphere should be considered zoon

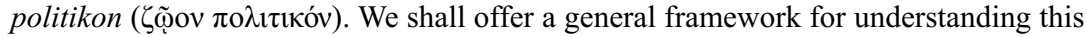
fundamental property of human beings, drawing in various ways on the historical development of the concept. This, in turn, has important implications for political theory, as it suggests that human beings are predisposed towards sociability: man is by nature a social animal that lives in community with others and can only achieve justice and the common good through dialogue and deliberation. As Aristotle pointed out,

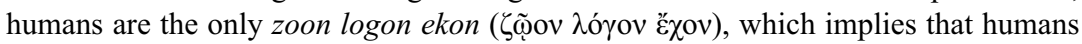
derive their political nature from their rhetorical nature.
\end{abstract}

\title{
KEYWORDS
}

Aristotle, political theory, rhetoric, zoon politikon.

\section{JUSTIFICACIÓN}

En este trabajo los autores quieren poner de relieve cómo un texto esencial en la historia del pensamiento político fue comentado durante siglos por autores de diferentes escuelas de pensamiento, creencias religiosas y contextos culturales buscando desentrañar el verdadero sentido de la famosa afirmación de Aristóteles (384-322 a. e. c.) que el hombre por naturaleza está destinado a vivir en comunidad:

De todo esto es evidente que la ciudad es una de las cosas naturales, y que el hombre, por naturaleza, es una especie de animal social. Por su parte, del sin ciudad por naturaleza y de aquel que, por su quehacer resulta ciertamente disminuido, o de aquel que es superior a un hombre, escuchamos a Homero vituperarlo por carecer de "fratría, ley y casa familiar", y que siendo así por naturaleza, tiene por ello una inclinación a la guerra como lo que ejecuta cada pieza aislada en el juego de damas. La razón por la que el hombre es un ser social, más que las abejas o que cualquier otra especie de animal gregario, es evidente: la naturaleza no hace nada en vano. El hombre es, por otra parte, el único que tiene un lenguaje inteligible. El sonido sirve para indicar el dolor y el placer; y eso es común a todos los animales, porque por 
naturaleza así se trasmite la sensación de dolor y placer. Ahora bien, el lenguaje inteligible sirve además para manifestar el propio interés así como lo dañino, o lo justo y lo injusto, siendo esto exclusivo del hombre que, así, se diferencia de los demás animales al tener, por ello, el sentido del bien y del mal, el de lo justo y de lo injusto y todo lo demás que le es propio ${ }^{2}$.

El texto, que tiene tras de sí una larga historia interpretativa, exige una cierta explicación para una adecuada comprensión de su contenido. No es de extrañar que llamara poderosamente la atención de los pensadores y comentaristas medievales y modernos. Nuestra propuesta es estudiar la constitución de la polis ( $\pi$ ó $\lambda \mathrm{\iota}$ ) desde el punto de vista del desarrollo histórico, mostrando que la naturaleza dotó al hombre de unas características que lo convertían en especialmente apto para iniciar y culminar ese desarrollo con éxito. Dicho proceso es un progreso vital que le lleva - y esta es la tesis de los autores - a considerarse social en la familia y termina siendo político en su pertenencia plena y activa en la polis. Por tanto, el hombre por su capacidad dialógica, por su necesidad vital y por su fuerza intelectual, es un ser que está destinado a cumplimentar el camino entre el simple vivir y el con-vivir, que es una manera de ser-con-otros, o dicho de otra forma, de completar su ser con los de otros que están junto a uno buscando la realización social e individual en la polis. Aristóteles es el pensador griego que nos acerca más a esta realidad política y, además, es el que la pudo contemplar y analizar en el momento en que se estaba produciendo un cambio de paradigma político y social: la polis comenzaba a perder su vitalidad y, por supuesto, ya no era ni mucho menos el horizonte político del hombre griego, que comenzaba a abrirse a otras realidades. No obstante, nos ha dejado estas palabras que han servido durante generaciones para definir esta realidad:

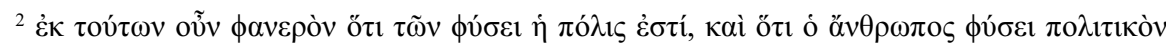

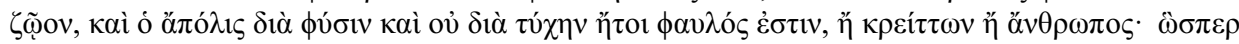

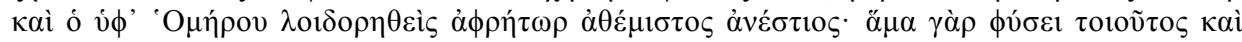

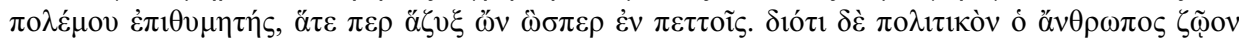

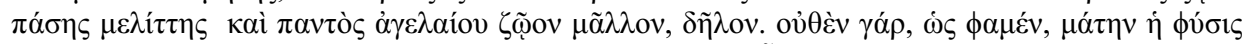

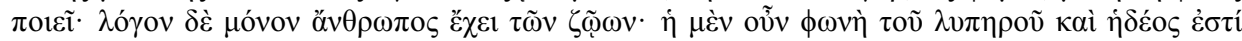

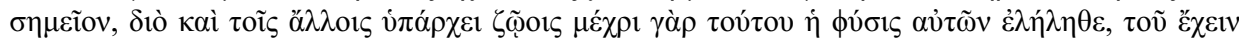

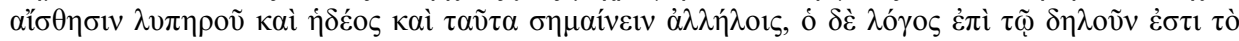

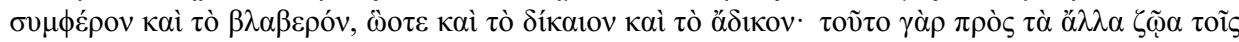

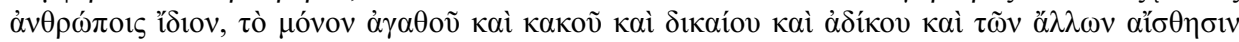

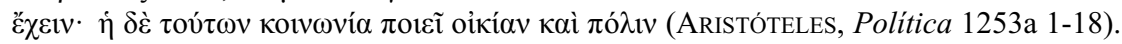


La comunidad perfecta de varias aldeas es ya la ciudad, porque tiene por así decirlo, la total autarquía, pues surgió para vivir pero es para vivir bien. Por ello, toda ciudad es por naturaleza, si es que lo son las primeras [familia y aldea]: en efecto, ella es el fin de aquellas y su naturaleza es ser fin $^{3}$.

Este es el modelo de polis que defiende y propone Aristóteles para el hombre, para todo hombre en todo tiempo, porque en ella, una vez superadas las limitaciones de las primeras organizaciones sociales - familia y aldea-, el ser humano encuentra satisfechas todas las existencias que le impone su modo de ser peculiar y que se destaca de otros animales. Esto es lo que vamos a ver en el siguiente epígrafe.

\section{TRAdiciones de INTERPRETACiÓN}

El pasaje de la Política 1253a 7-18 es clave para entender el pensamiento político aristotélico. Durante siglos ha sido traducido y comentado por diversos autores que han intentado desentrañar el verdadero sentido de la famosa afirmación de Aristóteles en la que el hombre, por naturaleza y no por ninguna otra concesión, está destinado a vivir en comunidad ${ }^{4}$.

El propósito de este apartado es ofrecer una investigación sistemática en torno a la interpretación de este pasaje, núcleo de la antropología política del autor griego, estudiando las principales traducciones y comentarios del mismo.

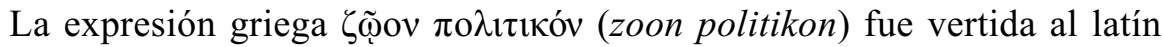
indistintamente como animal civile, animal sociale y animal politicum, entre otras. La versión por animal civile, que en principio aparece junto con animal politicum como doblete sinonímico, fue la preferida por la mayoría de traductores y comentaristas medievales y renacentistas vinculados a la tradición tomista, mientras que, en líneas generales, los autores vinculados a la tradición católica no tomista prefirieron traducirla por animal sociale.

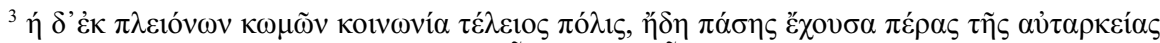

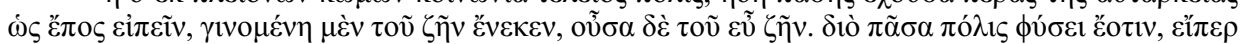

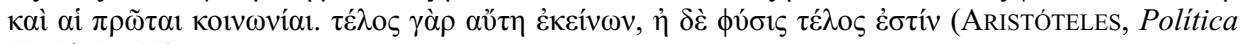
1252b 27-32).

${ }^{4}$ Un hecho que contrasta con la explicación que nos ofrece Platón (428/427-348/347 a. e. c.) en el mito que relata en el diálogo Protágoras 322 c y ss. En él, la intervención de los dioses con-

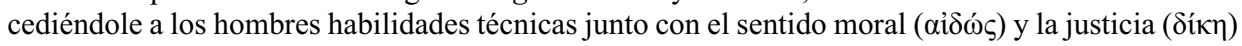
les permite a estos unirse para evitar ser exterminados por los animales. 
Entre los siglos catorce y dieciséis se impone progresivamente la traducción

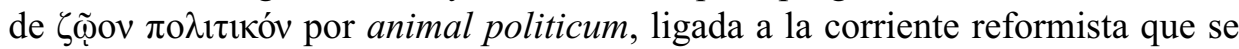
había desarrollado en Europa desde finales del siglo catorce, y en especial con el Renacimiento, y que cuestionaba los tradicionales principios de la religión católica así como la autoridad de la Iglesia de Roma. En esta época se elabora la imagen moderna del homo politicus, que desplaza el ideal virtuoso y republicano del estoicismo romano hacia un pragmatismo alimentado por los siguientes hechos. La política se inclina hacia el interés del Estado, en detrimento de la fuerza moral y espiritual, fomentando un nuevo tipo de moral, cívica, colectiva y social, sacralizada en la persona real. En consecuencia, este empleo marca una laicización creciente de las instituciones y la paulatina independencia de lo político frente a lo religioso. Resulta muy difícil precisar el límite donde se encuentran y separan los intérpretes. Las páginas siguientes podrían servir para explicar los presupuestos teóricos de esta multiplicidad de traducciones.

El origen de la difusión del término "política/político", como sustantivo y como adjetivo, se atribuye a la traducción francesa de la Política de Nicole Oresme (1320/1322-1382) en el siglo catorce ${ }^{5}$. El término politicus era ya frecuente en el latín medieval y tributario de la traducción de la Política (ca. 1264) de Guillermo de Moerbeke (1215-1286). Si el siglo quince supuso una importante inflexión en la filosofía política, el Renacimiento contribuyó al desarrollo del concepto de "político" y supuso el nacimiento de los sentidos principales que hoy conocemos:

- la política, como sustantivo, es "la ciencia y modo de gobernar la ciudad y república" o "el gobierno de la república, que trata y ordena las cosas que tocan a la policía, conservación y buena conducta de los hombres"7;

- el adjetivo "político", no como ciencia, sino como arte, que se refiere a la conducta del "sujeto versado y experimentado en las cosas del gobierno y negocios de la república o reino", o bien "el urbano y cortesano".

${ }^{5}$ Léopold DeLISLE, Observations sur plusieurs manuscrits de la politique et de l'économique de Nicole Oresme, A. Gouverneur, Nogent-le-Rotrou, 1870-1879; Jan Pieter Hubert KNoPS, Études sur la traduction française de la morale à Nicomache d'Aristote par Nicole Oresme, Excelsior, Gravenhage, 1953.

${ }^{6}$ Sebastián de Covarrubias Orozco, Tesoro de la lengua castellana o española, Luis Sánchez Impresor, Madrid, 1611, fol. 291v.

${ }^{7}$ Diccionario de la lengua castellana, Imprenta de la Real Academia Española, Madrid, 1737, tomo V, p. 312.

${ }^{8}$ Ibidem.

${ }^{9}$ Covarrubias Orozco, Tesoro de la lengua castellana o española, fol. $291 \mathrm{v}$. 
Entre otros, los factores que contribuyeron a la inflexión de este término en el Renacimiento se deben, como mencionábamos más arriba, a la propagación de la Reforma y de las guerras de religión que siguieron, a la recepción de la obra de Niccolò Machiavelli (1469-1527) y a la doctrina de la "razón de Estado" que se implanta como Realpolitik del momento. A partir del siglo die-

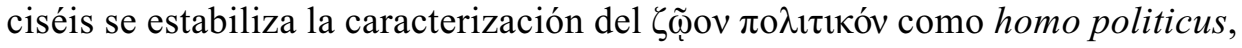
resultado de la superposición de las distintas interpretaciones del texto de Aristóteles.

\subsection{El hombre animal civil y político}

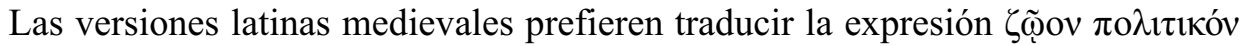
por animal civile, tal como evidencian no solo la primera versión latina, de Moerbeke ${ }^{10}$, sino también Alberto Magno (ca. 1200-1280) $)^{11}$ y Tomás de Aquino $(1225-1274)^{12}$ y la traducción francesa de Nicolás Oresme $(c a .1323-1382)^{13}$. Por su parte, para Jean Buridan (ca. 1300-1358), como también para Tomás de Aqui-

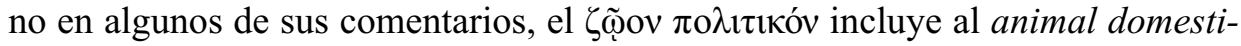
cum et civile, entendiendo que la familia y la ciudad forman una unidad ${ }^{14}$. Es evidente que en estas primeras versiones civile aparece en doblete sinonímico con politicum para explicitar el sentido de este último término, calco del griego politikon ( $\pi \mathrm{o} \lambda \iota \tau \iota \kappa o ́ v)^{15}$. En el Renacimiento, Jean Le Tourneur Versor (siglo quince), que sigue a Buridan, adopta también el doblete sinonímico civile et politicum ${ }^{16}$.

${ }^{10}$ ARISTÓTeles, Politica (I-II.11). Translatio prior imperfecta interprete Guillelmo de Moerbeka (?) [ca. 1264], en Petrus Michaud- Quantin (ed.), Aristotelis Latinus 29.1, Desclée de Brouwer, Bruges-Paris, 1961 ad 1253a7-9.

${ }^{11}$ Alberto Magno [Albertus Magnus], Ethicorum libri X. Politicorum libri VIII, Claude Prost, Lyon, 1651, p. 9 ad 1253a7-8.

${ }_{12}$ Tomás de Aquino, In octo Politicorum Aristotelis libros expositio, Eucharium Silber alias Franck, Roma, 1492, 1.1.36-37.

${ }^{13}$ Nicole Oresme, "Le Livre des Politiques d'Aristote" [ca. 1370-1377], ed. de Albert Douglas Menut: Transactions of the American Philosophical Society, n. ${ }^{\circ} 60$ (1970), p. 49.

${ }^{14}$ Jean BuRIDAN [Joannes Buridanus], Quaestiones in octo libros Politicorum Aristotelis, Guilielmus Turner, Oxford, 1640, 1.4, pp. 16-19.

${ }^{15}$ Nikolai RuBInSTEIN, "The history of the word politicus in early-modern Europe", en A. PAdgen (ed.), The Languages of Political Theory in Early-Modern Europe, Cambridge University Press, Cambridge, 1987, pp. 41-56.

${ }^{16}$ Jean Le Tourneur Versor [Joannes Versoris], Libri Politicorum Aristotelis cum commento multum utili et compendioso, Henricus Quentell, Colonia, 1492, f. 3a-4b, ad 1253a7-9. 


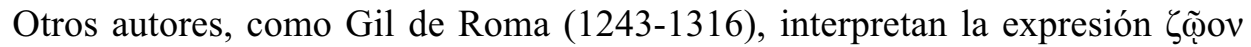
$\pi \mathrm{o} \lambda \iota \tau 1 \kappa o ́ v$ en toda su extensión, como animal sociale, civile et politicum ${ }^{17}$.

Con todo, la versión por animal civile sigue siendo la preferida por los traductores y comentaristas renacentistas vinculados a la tradición tomista y así se encuentra en Ludovicus Valentia (1453-1496) ${ }^{18}$, Juan Ginés de Sepúlveda (1490$1573)^{19}$, Michael Schütz (1514-1581) y Johannes Sturm (1507-1589) ${ }^{20}$, Denis Lambin (1519/20-1572) y Piero Vettori (1499-1585) ${ }^{21}$, Johannes Kessel (ca. 1546-1600) ${ }^{22}$, y también, a partir del siglo diecisiete, en Peter Gilken (15581616) ${ }^{23}$, Hubert van Giffen (1534-1604) ${ }^{24}$, Joannis Felde (?-1668) ${ }^{25}$, Christoph Heidmann (?-1627) ${ }^{26}$, Hermann Conring (1606-1681) $)^{27}$ y Johann Gottlob Schneider $(1750-1822)^{28}$.

En esta época los sinónimos politicus-civilis servirán para ir acentuando progresivamente la oposición entre el derecho civil y el eclesiástico. Como hemos visto en la definición de Sebastián de Covarrubias en su Tesoro de la lengua castellana o española $(1611)^{29}$, "civil" es "todo lo que pertenece al derecho

${ }^{17}$ GIL DE Roma [Aegidius Romanus], De regimine principum libri III, Bartolomeo Zanetti, Roma, 1607, p. 12 ad 1253a7-9.

${ }^{18}$ Ludovicus Valentia [Ludovicus Ferrariensis], Epitoma per conclusiones librorum Politicorum, Eucharius Silber, Roma, 1464: ad 1253a7-8.

19 Juan GinÉs DE SEPÚlveda [Johannes Genesius Sepulveda], Aristotelis de Republica libri VIII, Michael Vascosanus, Paris, 1548: ad 1253a7-9.

${ }^{20}$ Michael Schütz [Michael Toxites] y Johannes (o Jean) STURm [Ioannes Sturmius], Aristotelis Politicorum liber primus, Christopher Froschover, Zurich, 1550, pp. 17a-18a: ad 1253a7-9.

21 Denis Lambin [Dionysius Lambinus] y Piero Vettori [Petrus Victorius], Aristotelis Politicorum libri octo, Eusebius Episcopius, Basilea, 1582, pp. 6-7, 10 traducción de Vettori ad 1253a7-9 y traducción de Lambin ad 1253a7-9.

22 Johannes Kessel [Johannes Caselius], In libros Aristotelis de optimo statu Reipublicae, Stephanus Myliandrus, Rostock, 1587, pp. 22s.: ad 1253a7-8.

${ }^{23}$ Peter GILKen [Petrus Gilkenius], In Politicorum Aristotelis libros VIII, Zacharias Palthenius, Frankfurt, 1605, pp. 11-12: ad 1253a7-9.

${ }^{24}$ Hubert van GIFFEN [Hubertus Giphanius], In Politicorum opus Aristotelis, Lazar Zetzner, Frankfurt, 1608, pp. 29-33: ad 1253a7-9.

25 Joannis Felde, Analysis librorum Politicorum Aristotelis, Gerlachius-Beckensteinius, Frankfurt, 1654, pp. 21-23.

${ }^{26}$ Christoph HeIdmann [Christophorus Heidmanus], Dissertationes Politicae VII. Ex octo libris Politicorum Aristotelis, Johann Heitmüller, Helmstedt, 1672, pp. 20-21.

${ }^{27}$ Hermann Conring [Hermannus Conringius], Aristotelis Politicorum libri superstites. Editio nova, Henning Müller, Helmstedt, 1656, pp. 6-7: ad 1253a7-9.

28 Johann Gottlob ScHneIDER, Aristotelis Politicorum libri octo superstites, Taberna Librariae Academiae, Frankfurt (Oder), 1809, p. 343: ad 1253a7-9.

${ }^{29}$ Covarrubias Orozco, Tesoro de la lengua castellana o española, fol. 248. 
de la ciudad", mientras que el Diccionario de lengua castellana (1729) trae dos acepciones para el término "civil": a) "civil" es "lo que toca y pertenece al derecho de ciudad y de sus moradores y ciudadanos"; b) civil "en su recto significado vale sociable, urbano, cortés, político y de prendas propias de ciudadano; pero en este sentido no tiene uso, y solamente se dice del que es desestimable, mezquino, ruin y de baja condición y procederes" ${ }^{\prime 30}$.

En algunos comentaristas españoles vinculados a la tradición tomista es posible identificar el doblete sinonímico político-civil. Así, Alfonso de Cartagena (1384-1456) en El Oracional señala que:

$\mathrm{Al}$ omne podemos considerar en tres maneras: la primera es considerándole commo animal non aviendo respecto a la razon; la segunda es considerándole commo animal razonable, politico e civil non aviendo respecto a la ley divinal, mas solamente vacando a la manera humana que los juristas llaman el derecho de las gentes; la terçera considerándole commo animal razonable e catholico subjecto a la ley divinal ${ }^{31}$.

Rodrigo Sánchez de Arévalo (1405-1470) en Suma de la política escribe:

Toda cibdad es fundada por causa de vivir, ca los omes ayuntados en una cibdad o comunidad pueden ayudar y socorrer a los otros en las cosas que les fallecen, lo que no podrían fazer viviendo solitarios, quanto más que, como dize el Filósofo, el ome es animal sociable e apto a compañía e civilidad, onde no podría conservar esta su natura sin vivir en cibdad.

\section{Y más adelante:}

E por quanto, como dize el Filósofo en el primero de las Políticas, las cosas morales y políticas deven ser semejantes a las naturales cosas - como es dicho, toda arte deve juntar y semejar a la natura— pues, assí como la natura no solamente entiende a la ordinación y salvación de las cosas engendradas, assí el buen político no solamente deve entender en bien fundar y edificar la cibdad que es engendrarla, más aun deve entender en la ordenar y salvar, por bueno y prudente regimiento. $\mathrm{Ca}$ poco aprovecharía ser alguno buen fundador de la cibdad si no fuesse buen regidor

${ }^{30}$ Diccionario de la lengua castellana, tomo II, p. 364.

${ }^{31}$ Alfonso de CARTAGena, El Oracional [1456], edición crítica (comparación del manuscrito 160 de Santander y el incunable de Murcia) de Silvia González-Quevedo, Albatros-Hispanófila, Valencia-Chapel Hill, 1983, § 21. En esta cita y en las siguientes, respetamos la ortografía del original. 
della, porque la fundación se salva por buen regimiento, el qual no solamente conserva mas aun augmenta a las cibdades defectuosas y mal fundadas, y da un ser civil y político a los que eran incultos y silvestres ${ }^{32}$.

Pedro Marín en sus Sermones escribe:

E como el honbre aquí es dicho animal asociabile per naturam por respecto de los brutos, así el dicho Philósopho lo llama animal político e ceuil en respecto de los a él conformes en natura specífica con que ha de conveuir. E por quanto esta conueniencia tiene a los octros honbres e en sus neccessidades á vsar dellos e de sus cosas, es neccessario que declare su concepto e deseo a los convinientes. E esta declaración á de seer por señales comunes a todos, que si el que á neccessario la cosa notificasse su desseo por señal ho significación non común, ante ygnota, a aquél a quien tempta notificar e significar su concepto, su deseo sienpre estaría ascondido, e, así, en su neccessidade non sería proueído. Como si el gallego estando en Austria demandasse pan sin octra significaçión senon de pallabra al alamán que non entendiesse su lengua ${ }^{33}$.

Sin desaparecer por completo la dimensión "civil", propia del cristianismo tomista, como hemos apuntado, se produce también progresivamente un desplazamiento en las traducciones, que destacan cada vez más su sentido "social", "sociable" o "sociabilidad". Si bien estos términos no se recogen en el Tesoro de la lengua castellana o española (1611), el Diccionario de la lengua castellana (1739) define "sociedad" como "compañía de racionales", "sociable" como "lo que fácilmente se junta a otro e inclina a tener compañía” y "sociabilidad" como "el tratamiento y correspondencia de unas personas con otras". Da la impresión que la "sociabilidad" es definida a partir de la "racionalidad" — o, mejor, "lingüisticidad" o "comunicabilidad" — del ser humano ${ }^{34}$.

32 Rodrigo SÁnchez de Arévalo, Suma de la política [1454-1457], ed. de Mario Penna, Atlas, Madrid, 1959, § 1 y $\S 19$, p. 280.

${ }^{33}$ Pedro Marín, Sermones [1455], ed. de Pedro M. Cátedra, Universidad de Salamanca, Salamanca, 1990, § 10, p. 143.

${ }^{34}$ Diccionario de la lengua castellana, tomo VI, p. 133. 


\subsection{La dimensión social}

Es precisamente durante el Renacimiento cuando comienza a entenderse el $\zeta \tilde{\omega} o v$

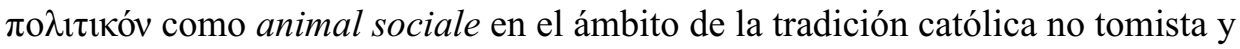
en el movimiento reformado. Así lo recoge Leonardo Bruni (ca. 1370-1444) en su traducción latina, cuya versión española, publicada en 1509, vierte por "animal sociable" ${ }^{35}$. En el ámbito hispánico tenemos a Pedro de Castrovol (siglo quince), que traduce como civile et associabile ${ }^{36}$, y a Fernando de Roa (ca. 14481507), que en su traducción sigue a Bruni, mientras que en el comentario sigue la tradición tomista ${ }^{37}$. Acentúan también esta dimensión "social": en el ámbito francés, el humanista Jacques Lefèvre d'Étaples (1450-1537) 38 ; en el ámbito alemán, destacan los reformados Virgilius Wellendorffer (siglo dieciséis), que distingue entre "civil" y "social"39, Philipp Melanchthon (1497-1560) ${ }^{40}$ y Joachim Kammermeister (1500-1574) $)^{41}$; en el ámbito italiano, Chrysostomus Javelli (ca. 1470-1538), que opta por la versión animal politicum et sociale ${ }^{42}$, Raffaello Maffei (1451-1522) ${ }^{43}$, Donato Acciaioli (1429-1478) ${ }^{44}$, Genesio Malfanti (siglo

${ }^{35}$ Leonardo BRUNI [Leonardo Aretino], Aristotelis Politicorum libri octo, S. Colinaei, Paris, 1526. Leonardo Bruni., Aristóteles: Política y Económica, Jorge Coci Alemán, Zaragoza, 1509: "...de lo qual pareçe el hombre ser animal sociable mas que todas las avejas y todo otro ganado" (ad 1253a7-9).

${ }^{36}$ Pedro de Castrovol, Commentum super libros Politicorum et Oeconomicorum Aristotelis, Arnaldo Guillermo de Brocario, Pamplona, 1496.

${ }^{37}$ Fernando DE ROA [Ferdinandus Rhoensis], Commentarii in Politicorum libros, Joannes de Porres-Joannes de Zaraus, Salamanca, 1502, pp. VIIs.: ad 1253a7-9.

${ }^{38}$ Jacques LeFÈVRE D’ÉTAPLES [Jacobus Faber Stapulensis], Introductio in Politica Aristotelis, Stephanus, Paris, 1512, ad 1.2.10.

39 Virgilius Wellendorffer (Wellendarffer), Polilogium ex Aristotelis octo Politicorum libris, Monacenses, Leipzig, 1513, f. 8b.

${ }^{40}$ Philipp Melanchthon [Philippus Melanchton], In Aristotelis aliquot libros Politicos commentaria, Johann Setzer, Haguenau, 1531, ff. 4s.

${ }^{41}$ Joachim KammermeIster [Joachim Camerarius der Ältere], Politicorum et Oeconomicorum Aristotelis interpretationes et explicationes accuratae, Andreas Wechel, Frankfurt, 1581.

${ }^{42}$ Chrysostomus Javeldi (Chrysostomus de Casali), Epytomata in octo libris Politicorum, Stephanum de Sabio, Venecia, 1536, 1.4, f. 5b-6a.

${ }^{43}$ Raffaello Maffer [Raphael Maffeius Volaterranus], Politica ad Nicomachum, Raphaelis Volaterrani argumenta in eosdem. Leonardo Aretino interprete. Hieronymus Scotus, Venecia, 1542, p. 6.

${ }^{44}$ Donato Accialoli, In Aristotelis libros octo Politicorum commentarii, Vicentius Valgrisius, Venecia, 1566, p. 16ab. 
dieciséis), que emplea animal civile et sociale ${ }^{45}$, al igual que el dálmata Nikola Vitov Gučetić (1549-1610), que usa animale civile et sociabile en su comentario escrito en italiano ${ }^{46}$. En el siglo diecisiete Pierre de la Ramée (1515-1572) prefiere traducir por civilius et urbani animal ${ }^{47}$.

Entre los autores renacentistas españoles que participan de una interpreta-

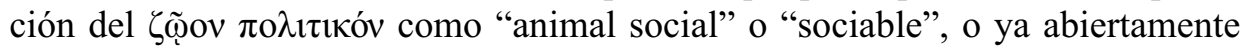
como "animal político", encontramos a fray Antonio de Guevara (1480-1545), quien en su Relox de príncipes señala:

Los antiguos philósophos, difiniendo qué cosa era hombre, dezían que el hombre era un animal que de su propria naturaleza era comunicable, sociable y risible, de do se sigue que el hombre encogido y solitario no puede en su condición sino ser enojoso ${ }^{48}$.

${ }^{45}$ Genesio Malfanti [Genesius Malfantius], Civilis philosophiae compendium. In quo quidquid in libris Ethicorum, Politicorum, et Oeconomicorum disseruit Aristoteles, Paulus Meietus, Padova, 1587, p. 43b.

${ }^{46}$ Nikola Vitov GuČETIĆ [Niccolò Vito de Gozze], Dello stato delle republiche, secondo la mente di Aristotele, Aldo Manuzio, Venecia, 1591, pp. 20-21.

${ }^{47}$ Pierre DE LA Ramée [Petrus Ramus], Aristotelis Politica, Claudius Marnius y Ioannes Aubrius, herederos de Andreas Wechel, Frankfurt, 1601, pp. 13-14: ad 1253a7-9. Ramus señala la complementariedad entre civitas y urbs. Ya en el siglo sexto, San Isidoro de Sevilla (560-636) escribe en sus Etimologías (15.2) lo siguiente: "Civitas es una muchedumbre de personas unidas por vínculos de sociedad, y recibe ese nombre por sus ciudadanos (cives), es decir, por los habitantes mismos de la urbe [porque concentra y encierra la vida de mucha gente]. Con el nombre de urbe (urbs) se designa la fábrica material de la ciudad, en tanto que civitas hace referencia, no a sus piedras, sino a sus habitantes". En este texto nos explica San Isidoro de Sevilla que la palabra latina civitas designa una pluralidad de seres humanos unidos por lazos sociales y debe su nombre al de los ciudadanos (cives), es decir, a los habitantes de la urbs, que concentra y abarca, dentro de sus muros, la vida de muchos. Con la palabra urbs se designa la fábrica o estructura material de la ciudad, mientras que la palabra civitas se refiere a los ciudadanos, no a las piedras. En este sentido, en Las Etimologías romanceadas de San Isidoro [1450], ed. de Joaquín González Cuenca, Universidad de Salamanca-CSIC-Diputación de León, Salamanca-León, 1983, p. 203, se señala: "E actualis es dicha la [parte de la Filosofía] que por sus obras demuestra las cosas propuestas. De la qual son tres partes: moralis, que fabla de las costumbres, dispenssativa, que es 'compartidor' o 'ordenador', civilis, que fabla de las cosas de la çibdat. Moralis es dicha aquella por la qual es cobdiçiada o demandada honesta costumbre de bivir. Dispenssativa es dicha quando el ordenamiento de las cosas de casa es fecho sabiamente. Civilis es dicha por la qual es catado e departido el pro de toda la çibdat".

${ }^{48}$ Fray Antonio de Guevara, Relox de Príncipes [1529-1531], ed. de Emilio Blanco, ABL Editor, Madrid, 1993, p. 405. En esta cita y en las siguientes, respetamos la ortografía del original. 
Y más adelante:

Como el hombre naturalmente sea político, que es ser amigo de compañía, la compañía engendra embidia; la embidia pare discordia; la discordia cría la guerra; la guerra levanta la tyranía; la tyranía dissipa a la república; y, perdida la república, tienen todos en peligro la vida. Por esso es muy necessario que en todo ayuntamiento muchos se rijan por uno, que al fin al fin no ay república bien regida si no la que por un solo bueno es governada ${ }^{49}$.

Otro importante humanista, Juan de Arce de Otálora (ca. 1510/1515-1561) en sus Coloquios de Palatino y Pinciano escribe: "El hombre, dice el Filósofo que es animal sociable y alegre y conversable". Y más adelante añade: "El hombre, según Aristótil, es animal sociable, y el mal acondicionado no se puede llamar tal" 50 . El célebre Juan Huarte de San Juan (1529-1588) en Examen de ingenios para las ciencias afirma:

El hombre es animal racional, sociable y político; y porque su naturaleza se habilitase más con el arte, inventaron los filósofos antiguos la dialéctica, para enseñarle como había de raciocinar, con qué preceptos y reglas, cómo había de definir las naturalezas de las cosas, distinguir, dividir, inferir, raciocinar, juzgar y elegir, sin las cuales obras es imposible ningún artífice poderse pasar. Y para poder ser sociable y político, tenía necesidad de hablar y dar a entender a los demás hombres las cosas que concebía en su ánimo; y porque no las explicase sin orden ni concierto, inventaron otra arte que llaman retórica, la cual con sus preceptos y reglas le hermosea su habla con pulidos vocablos, con elegantes maneras de decir, con afectos y colores graciosos ${ }^{51}$.

\subsection{Las interpretaciones posteriores a las guerras de religión}

Antes de las guerras de religión que asolaron Europa, entre ellas la Guerra de los Treinta Años que provocó un cambio de hegemonía mundial, se había hecho un uso neutro del adjetivo "político", que se refería a todo aquello "relativo al gobierno". Así, desde el siglo doce el término civilis aparecía como doblete sinonímico de politicus, para explicitar el sentido de este último.

\footnotetext{
${ }^{49}$ Ibid., pp. 243-244.

${ }^{50}$ Juan DE ARCE DE OtÁlora, Coloquios de Palatino y Pinciano [ca. 1550], ed. de José Luis Ocasar Ariza, Turner, Madrid, 1995, I, 62 y 587, respectivamente.

${ }^{51}$ Juan Huarte DE SAn JuAn, Examen de ingenios para las ciencias [1575-1588], ed. de Gui1lermo Serés, Cátedra, Madrid, 1989, pp. 433-434.
} 


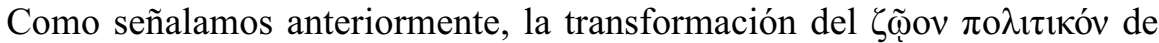
Aristóteles en un animal civile procede de la traducción de Moerbeke. Esta interpretación servirá para ir acentuando progresivamente la oposición entre el derecho civil y el eclesiástico, siendo el germen de una concepción secularizada de la política. El uso creciente de animal civile en conjunción con animal politicum por muchos humanistas contribuirá a una identificación de la politia y la respublica. Ambas circunstancias propiciarán que a principios del siglo quince lo político se oponga, por una parte, a lo teológico, siendo sinónimo de "cívico" y, por otra parte, a lo monárquico, siendo sinónimo de "republicano".

Así, progresivamente la política fue concibiéndose tal como hemos citado "la ciencia y modo de gobernar la ciudad y república", según el Tesoro de la lengua castellana o española de Sebastián de Covarrubias, y englobando las demás artes cívicas, tal como recoge el Diccionario de la lengua castellana, que la entiende como "el gobierno de la república, que trata y ordena las cosas que tocan a la policía, conservación y buena conducta de los hombres".

Tras las guerras de religión se impuso, en los países reformados, la inter-

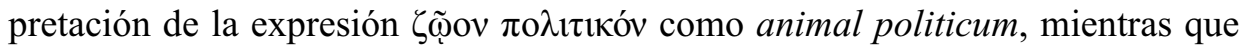
entre los católicos prevaleció el sentido de animal civile o animal sociale.

La nueva concepción de la política se distancia progresivamente de la ética. El final de la Edad Media consagró dos grandes principios que establecían el principio del derecho: uno descendente, teocrático y agustiniano - el poder procede de Dios-; otro ascendente y cívico, por el ascenso de los sujetos hacia el príncipe a partir de la definición aristotélica del hombre ${ }^{52}$.

Así, en el ámbito protestante alemán, Johann Kahl (1550-1614), destacado profesor de derecho en Heidelberg, discípulo del humanista francés Hugues Doneau (1527-1591) y autor de un célebre Lexicon iuridicum publicado en Frankfurt en 1600 y del que se imprimieron al menos catorce ediciones entre 1600 y 1673, en su traducción de la Política de Aristóteles, publicada en 1595,

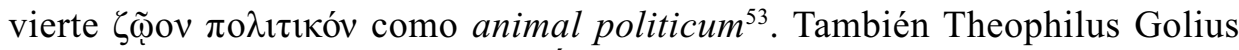
(1528-1600), profesor de Lógica y Ética en la Universidad de Estrasburgo desde 1572, en su Epitome doctrinae politicae lo interpreta en este mismo sentido ${ }^{54}$.

${ }^{52}$ Gianfranco FioraVAntI, "La réception de la Politique d'Aristote au Moyen Âge tardif", en Yves-Charles ZARKA (dir.), Aspects de la pensée médiévale dans la philosophie politique moderne, Presses Universitaires de France, Paris, 1999, pp. 4-24.

${ }^{53}$ Johann KaHL [Joannes Calvinus], Notae in Politicos Aristotelis priores libros, Peter Fischer, Frankfurt, 1595, p. 11. 
Y lo mismo hace Wolfgang Heider (1558-1626), profesor de Ética y Política en la Universidad de Jena, de la que llegó a ser rector en dos ocasiones, 1591 y $1607^{55}$. También, entre los católicos alemanes, Michael Piccart (1574-1620), profesor de Lógica, Poética y Metafísica desde 1599 en la Universidad de

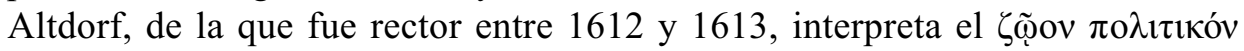
como animal politicum ${ }^{56}$. Sus fuentes son a la vez la tradición del aristotelismo italiano y el conocimiento de la nueva escolástica española. Entre los protestantes holandeses, Franco Petri Burgersdijk (1590-1635), que también

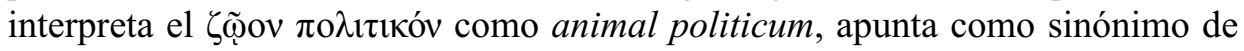
politicum la expresión maxime sociabile ${ }^{57}$.

En las interpretaciones protestantes del homo politicus tiende a desaparecer la dimensión mística o supranatural de un poder ahora secular, en manos de la sociedad civil ${ }^{58}$. En estas interpretaciones se da la emergencia de la idea de sociedad civil como resultado del cuestionamiento de los modelos de ordenación social y de autoridad existentes, que se desarrollará durante los siglos diecisiete y dieciocho. Así se encuentra en la obra de Balthasar Keller (1614-1671), famoso teólogo evangelista que compatibilizó varios puestos docentes en la Universidad de Helmstedt con su dedicación pastoral como predicador y pastor ${ }^{59}$, y en Gebhart Theodor Meier (1633-1693), autor de importantes obras de derecho canónico e historia eclesiástica ${ }^{60}$.

Todo esto nos ofrece un esbozo, que sin duda es necesario completar, de la

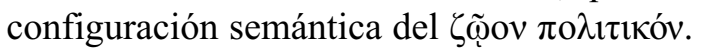

${ }^{54}$ Theophilus Golius, Epitome Doctrinae Politicae ex octo libris Politicorum Aristotelis, Herederos de Josias Richelius, Strassburg, 1622, pp. 20-21.

${ }_{55}^{5}$ Wolfgang HeIDER, Philosophiae politicae systema, Johann Reiffenberger, Jena, 1628, pp. 29-30: "2. Homo natura est animal Politicum...2.

${ }_{56}$ Michael PicCart [Michael Piccartus], In Politicos libros Aristotelis commentarius, Lorentz Kober, Leipzig, 1615, pp. 44-49.

${ }^{57}$ Franco Petri BurgersDiJK [Franciscus Burgersdicius], Idea oeconomicae et politicae doctrinae, Hieronymus de Vogel, Leiden, 1644, p. 6 y p. 33.

${ }^{58}$ John Ehrenberg, Civil Society. The Critical History of an Idea, New York University Press, New York, 1999.

${ }^{59}$ Balthasar KelLer [Balthasar Cellarius], Politicae Succinctae, Lobenstein, Jena, 1664, pp. 4-5.

${ }^{60}$ Gebhart Theodor MeIER, Aristotelis Politicorum analysis ac expositio usibus studiosorum, Jacobus Müller, Helmstadt, 1668, pp. 16-18. 


\section{EL HOMBRE ES UN SER QUE VIVE Y CON-VIVE}

En las páginas precedentes hemos espigado algunas opiniones entre los muchos comentarios que existen a la Política de Aristóteles. No obstante, para completar este trabajo habría que proceder a un estudio más minucioso de las traducciones y comentarios, así como libros inspirados en la obra de Aristóteles ${ }^{61}$. Las consideraciones que haremos en este epígrafe las dividiremos en dos partes. Primero, se expondrán diez temas relevantes que los comentaristas y críticos del texto han vislumbrado en él. Segundo, se insistirá en la necesidad de organizarse políticamente por parte de los hombres como una dimensión de su capacidad para establecer relaciones con otros seres de forma organizada y estable.

\subsection{Temas relevantes que plantea el texto de Aristóteles}

Consideramos que, entre los muchos aspectos que han llamado la atención a los comentaristas, los más interesantes podrían ser los siguientes.

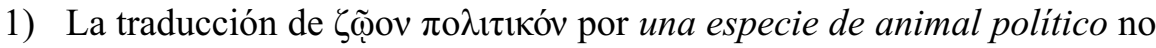
expresa suficientemente el profundo sentido de la frase. Se puede admitir siempre que se busque una justificación en el hecho de que la terminología de Aristóteles es muy clara: el hombre es una especie política, un ser gregario que se agrega en una comunidad ordenada bajo un dispositivo de mando y obediencia. En esa comunidad política el nexo de unión es un mecanismo de trato ordenado por medio del regimiento, de modo que en esa trama básica solo hay gobernante y gobernados que, a su vez, integran unidades más pequeñas que se cierran en la casa familiar, por debajo de la cual ya no hay nada más. Debe tenerse presente que la categoría teórica de sociedad es moderna y no se corresponde con las comunidades antiguas. Tampoco cabe describir al cuerpo político como sociedad; en realidad es una comunidad en la cual y de la cual todos participan. En rigor, la sociedad como espacio neutro de agregación de individuos indiferenciados es un resultado tardío de la

${ }^{61}$ Véase Salvador Rus Rufino, Comentarios a la Política de Aristóteles en la Europa medieval y moderna (siglos XIII al XVII), Fundación Hernando de Larramendi, Madrid, 2008, donde el autor ofrece un panorama completo de la recepción de la Política de Aristóteles. 
civilización occidental que tiene su origen cuando se asentó en las ciudades una nueva clase de hombre que crea su identidad únicamente con referencia a sí mismo y a su patrimonio, este es el burgués. El término

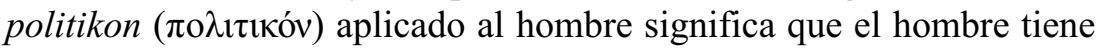
las virtudes y las condiciones físicas y psíquicas necesarias para convivir con otros, pero tenerlas de forma pasiva no es suficiente para constituir una ciudad. Es preciso poner en juego las capacidades, las facultades, mediante el esfuerzo para desarrollarlas, y la educación, que implica, de un lado, la acción de agentes exteriores, de otro, el empeño personal para aprender y dejarse guiar por alguien que sabe más, o conoce el camino, como expone Aristóteles ${ }^{62}$.

2) Para ser y vivir como animal solo es necesario tener sensaciones de placer y dolor. Para ser animal social, político, cívico o retórico se exigen otras características: lenguaje inteligible para comunicarse, inteligencia para elaborar proyectos, entender y distinguir lo bueno de lo malo, lo justo de lo injusto. Estas cualidades permiten establecer la forma de convivencia y desarrollarla ${ }^{63}$. Lo cual significa que el hombre es capaz de llevar a cabo tareas en común, con esfuerzos y medios coordinados, algo que el animal no puede. Aristóteles además introduce una novedad: el hombre adquiere el sentido moral sólo viviendo en sociedad, no es un regalo que le concede el nacimiento, sino una consecuencia de su condición de hombre que se va haciendo sociable y político en el transcurso de la vida. Estas ideas están expresadas en la Política ${ }^{64}$ así como en la Ética a Nicómaco ${ }^{65}$, y tienen su precedente en la República de Platón, donde se sostiene que el origen de la familia y, por tanto, de la ciudad está estrechamente relacionado con la evolución histórica de las comunidades primigenias: la casa familiar y la aldea ${ }^{66}$. El término final del proceso es la pertenencia a una polis, que es una construcción humana, porque el hombre es el único que tiene las cualidades necesarias y

${ }^{62}$ Véase Ética a Nicómaco 1169 b 16 y ss.

${ }^{63}$ Véase el estudio de Jaime Araos SAN Martín, La filosofía aristotélica del lenguaje, EUNSA, Pamplona, 1999; Gianluca SAdUn BoRdoni, Linguaggio e realtà in Aristotele, Laterza, Roma, 1994; Anne Cauquelin, Aristote: le langage, PUF, Paris, 1990; Walter Belardi, Il linguaggio nella filosofia di Aristotele, K Libreria Editrice, Roma, 1975; Miriam Th. LARKIN, Language in the Philosophy of Aristotle, Mouton, The Hague, 1971.

${ }^{64}$ Aristóteles, Politica $1280 \mathrm{~b} 5$.

${ }^{65}$ ARISTÓTeles, Ética a Nicómaco 1167b 2.

${ }^{66}$ Platón, República $484 \mathrm{~d}$. 
exclusivas para constituirla, los animales carecen de estos atributos, por tanto, no pueden organizarse de esta manera.

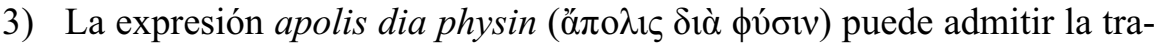
ducción por sin ciudad por naturaleza, es decir, alguien que se encuentra existencialmente apartado de cualquier tipo de comunidad política y, por ende, sin anclaje propio entre sus congéneres. Esto no significa que no habiten o se recojan al amparo de una casa, de una aldea o de una ciudad. Aristóteles pone el acento en la total carencia de pertenencia como sujeto que participa y considera suya propia la comunidad en la que se asienta. En rigor, como recoge el autor en palabras de Homero, se trata de aquellos que no tienen residencia, ni ley, ni casa familiar propias. Eso o son menos o son más que el hombre libre que como tal participa de la comunidad política y determina su identidad por esa pertenencia a la polis.

4) Para Aristóteles el que ama la guerra, quien provoca conflictos armados para resolver las diferencias, es una persona vil ${ }^{67}$.

5) La comparación interesa más que la referencia al juego en sí y esto se advierte en el uso de axys ( $\alpha \zeta v \xi)$, adjetivo que significa "aislado - no sometido a yugo". La función de cada pieza en el juego de las damas solo se orienta a capturar o suprimir a la pieza contra la que se enfrenta - esa es su causa eficiente-; y esa función es, además, un propósito que se agota en su acción. La esencia de cada pieza, o sea, lo que le hace ser esa pieza y ejercer esa función en el juego, carece pues de telos ( $\tau \dot{\lambda} \lambda \circ \varsigma$ ) o causa final que, sin embargo, sí lo tiene el juego como tal, pero no cada pieza aislada y fuera de contexto. El apolis (ä́ $\pi \mathrm{o} \imath \varsigma$ ) está pues, para Aristóteles, en la misma posición que la pieza de un juego de damas y por eso le asigna el atributo de violencia funcional como rasgo inherente, ya que no tiene más que eso. Así como el esclavo pertenece al que lo rige, la pieza, en ese mismo sentido, pertenece al juego y no tiene identidad propia, pues fuera del juego no es nada más que un objeto incierto, como el individuo sin residencia, sin ley propia recibida y sin casa familiar. Como se ve estamos ante una construcción lógica que solo se explica teniendo en cuenta los presupuestos de la filosofía pri-

${ }^{67}$ Véase Ética a Nicómaco 1177 b 9 y ss. y las palabras de indignación que Zeus dirige a Ares en la Ilíada vv. 890 y ss. reprochándole su conducta. 
mera de Aristóteles. Este es un buen ejemplo de conexión contextual que se va encontrar, en forma repetida, en el texto de la Política.

6) ¿Es el término politikon ( $\pi \mathrm{0} \lambda \iota \tau \iota \kappa o ́ v)$ propio del hombre y solo se predica metafóricamente del resto de los animales? O más bien, ¿la definición aristotélica se refiere a una característica zoológica elemental común a los miembros de las especies gregarias que cooperan en una tarea común? El texto aristotélico no dice que los hombres sean los únicos animales sociales, sino que son animales sociales en mayor grado que otros animales ${ }^{68}$. Frente a ciertas lecturas que consideran que el

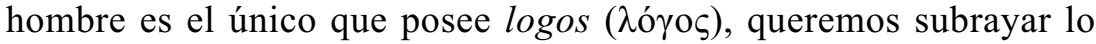
tosco de estas interpretaciones: muchos intérpretes, al sostener que el hombre es el único animal social, incurren al menos en dos ideas equivocadas sobre el sentido de la afirmación aristotélica. Unos, encontrando en Aristóteles un magnífico aliado contra el individualismo liberal al que se oponen, mantienen la superioridad de la vida política sobre otros modos de vida ${ }^{69}$. Pero esta interpretación de la política como un bien en sí mismo se topa con las observaciones de Aristóteles al final de la Ética a Nicómaco y la Politica, donde se afirma la superioridad del bios theo-

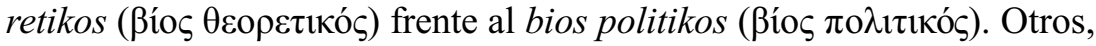
convirtiendo a Aristóteles en un determinista biológico, se apoyan en la afirmación de que "en todos existe por naturaleza el impulso (o $\rho \mu \eta ́)$ hacia tal comunidad"70 y no dudan en mantener que Aristóteles viene a decir que tenemos un impulso natural — biológicamente heredado-

${ }^{68}$ José Luis Ramírez, "Tópica de la responsabilidad. Reivindicación de la retórica para la ciudadanía moderna", en Jesús ConILl y David A. Crocker (eds.), Republicanismo y educación cívica ¿Más allá del liberalismo?, Comares, Granada, 2003, pp. 220-223; José Luis RamíRez, "La Retórica, pórtico de la ciencia": Elementos, n. ${ }^{\circ} 50$ (2003), pp. 3-4; Stephen S. SALKEVER, "Aristotle's Social Science", en Carnes Lord y David K. O'ConNor (eds.), Essays on the Foundations of Aristotelian Political Science, University of California Press, Berkeley, 1991, pp. 24-30; Stephen S. SAlKeVer, "Woman, Soldiers, Citizens: Plato and Aristotle on the Politics of Virility", en Essays on the Foundations of Aristotelian Political Science, pp. 173-176.

${ }^{69}$ Hannah Arendt, The Human Condition, The University of Chicago Press, Chicago, 1958, pp. 19, 26 y 194; John G. A. Pocock, The Machiavellian Moment. Florentine Political Thought and the Atlantic Republican Tradition, Princeton University Press, Princeton, 2003, p. 550 (existe traducción al español: El momento maquiavélico: el pensamiento florentino y la tradición republicana atlántica, Tecnos, Madrid, 2008, $2^{\mathrm{a}}$ edición); y Martha C. Nussbaum, The Fragility of Goodness: Luck and Ethics in Greek Tragedy and Philosophy, Cambridge University Press, Cambridge, 1986, pp. 345-353, todos ellos incurren en esta lectura equivocada del texto aristotélico.

${ }^{70}$ Aristóteles, Política 1253a 29-30. 
que nos lleva a vivir juntos ${ }^{71}$. Sin embargo, para Aristóteles ${ }^{72}$, el fin de

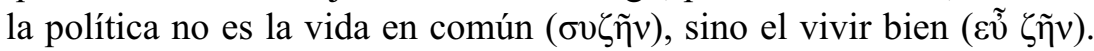
No se trata pues de impulsos determinados biológicamente, sino de inclinaciones potenciales modificables de acuerdo con la experiencia. En definitiva, que el hombre sea un animal social no es resultado ni de la superioridad de la vida política sobre otros modos de vida ni fruto de un impulso biológico necesario. Para Aristóteles, la política no es ni un fin en sí misma ni algo inevitable, sino que es el modo más razonable de organizar la pluralidad de inclinaciones y necesidades que conforman nuestra herencia biológica, una actividad fruto de nuestro deseo de vivir bien $(\varepsilon \tilde{v} \zeta \tilde{\eta} v)$. Los seres humanos son los únicos que tienen capacidad para sentir lo que es mejor para ellos y ordenar sus vidas de acuerdo con esto. Solo desde estos supuestos es posible comprender el alcance de este texto aristotélico.

7) Se ha optado por seguir la traducción común, pero el sentido de la frase apunta hacia que la naturaleza no hace nada que no se pueda comprender y explicar. En este sentido, la inteligibilidad para Aristóteles se configura como un proceso al que se accede por el conocimiento de las causas - material, formal, eficiente y final — tal como se las explica en sus lecciones de filosofía primera ${ }^{73}$. En este sentido, podemos poner a modo de ejemplo, cómo las cuatro causas tienen relación con los problemas que plantea la teoría política:

- La causa material, aquello de lo que está hecho algo, y así también la reunión en tanto pura agregación lo mismo que las casas serían la causa material de la ciudad ${ }^{74}$.

- La causa formal aquello que lo lleva ser algo y así también el gobierno constitucional sería una de las causas formales de la ciudad ${ }^{75}$.

${ }^{71}$ Para una severa crítica a esta posición, véase Allan GotTHELF, "Aristotle's Conception of Final Causality": Review of Metaphysics, n. ${ }^{\circ} 30$ (1976), pp. 226-254; Martha C. NussBAUM, "Aristotle on Teleological Explanation", en Aristotle's De Motu Animalium: Text with Translation, Commentary, and Interpretative Essays, Princeton University Press, Princeton, New Jersey, 1978, pp. 59-106; David W. BaLme, "Aristotle's Biology Was Not Essentialist": Archiv für Geschichte der Philosophie, n. ${ }^{\circ} 62$ (1980), pp. 1-12.

${ }^{72}$ ARISTÓteles, Política $1280 \mathrm{~b}$ 39-1281a 4.

${ }^{73}$ Véase ARISTÓTELES, Metafisica 994b 4-15.

${ }^{74}$ Aristóteles, Política 1253a 18-29.

${ }^{75}$ Ibid., 1278 b 8-10. 
- La causa eficiente sería aquello que impulsa o genera

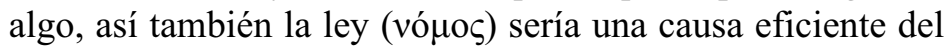
gobierno de una ciudad ${ }^{76}$.

- La causa final es el propósito o fin con arreglo al cual la cosa es lo que es, o llega a ser lo que es, y así también la polis en tanto que una comunidad donde participan los hombres, sería la causa final de la convivencia ciudadana ${ }^{77}$, y el ideal de bien ( $\tau$ ò $\varepsilon \tilde{j} \zeta \tilde{\eta} v)^{78}$, pero asimismo la causa final del buen vivir en la comunidad política no sería la mera convivencia de individuos diferentes y jerárquicamente relacionados, sino la práctica de las buenas acciones ${ }^{79}$.

8) El sentido del término logos ( $\lambda$ ó $\gamma \circ \varsigma$ ) en este pasaje es radicalmente opuesto a muchas interpretaciones actuales que convierten a Aristóteles en una especie de valedor de la teoría de los actos de habla. Para estos exegetas, Aristóteles vendría a sostener que el logos tiene como propósito facilitar el intercambio de información entre las personas, reduciendo así su significado al de mera phone $(\phi \omega v \eta ́))^{80}$. El logos nos posibilita, en cambio, el descubrimiento, a través de la deliberación, de los medios y los fines con los que organizar nuestras vidas. Esta capacidad del logos es una potencialidad que puede desarrollarse o no, pues los seres humanos son capaces de vivir bien o de vivir mal.

9) La traducción de phone como sonido, aunque también se podría entender como voz, se justifica porque Aristóteles se refiere a los animales. Es preferible dar el sentido de algo no articulado y comprensible, y esto se corresponde con los sonidos que emiten los animales ${ }^{81}$. El mismo Sócrates consideraba que el lenguaje era un requisito necesario para establecer la vida política, constituir la sociedad donde los hombres vivieran $^{82}$.

\footnotetext{
${ }^{76}$ Ibid., $1280 b$ 5-12.
}

${ }^{77}$ Ibid., 1261a 24-25; 1280a 34-1280b 5.

${ }^{78}$ Ibid., 1280b 39-40.

${ }^{79}$ Ibid., 1281a 2-4.

${ }^{80}$ Antonio LóPez EIRE, Actualidad de la Retórica, Ediciones Universidad de Salamanca, Salamanca, 1995, p. 46; y del mismo autor, Sobre el carácter retórico del lenguaje y de cómo los antiguos griegos lo descubrieron, UNAM, México, 2005.

${ }^{81}$ Véase ARISTÓTELES, Ética a Nicómaco 1170b 11-14, y otros autores como IsócraTES, Sobre el cambio de fortunas 253-257 y Nicocles 50.

${ }^{82}$ Jenofonte, Recuerdos de Sócrates 4.3.12. 
10) La marcada distinción entre casa (oỉí́ $)^{83}$ y ciudad ( $\pi$ ó $\lambda ı \varsigma$ ), sostenida sobre todo por aquellos intérpretes que afirman la superioridad de la vida política sobre otros modos de vida, no es tal en Aristóteles, pues ambas contribuyen al fomento del vivir bien $(\varepsilon \tilde{\tilde{\zeta}} \zeta \tilde{\eta} v)^{84}$. Para Aristóteles, el fin del hogar no es simplemente la procreación, pues "en la casa se encuentran, ante todo, los principios y las fuentes de la amistad, de la organización política y de la justicia" ${ }^{85}$. Esto subraya la importancia de la familia, recinto donde, a través de la educación ( $\pi \alpha 1 \delta \varepsilon i ́ \alpha)$, se adquiere el sentido de identidad personal necesario para poder delibe$\operatorname{rar}^{86}$. Uno de los principales objetivos de la educación es preparar a los jóvenes para que puedan deliberar sobre lo que es justo e injusto, de modo que se conviertan en ciudadanos diligentes ( $\sigma \pi 00 \delta \alpha$ ĩo $)$ y autónomos, es decir, capaces de gobernarse a sí mismos y de gobernar la ciudad $^{87}$. Tarea de los ciudadanos es pues juzgar qué diferencias potenciar y cuáles rechazar por ser perjudiciales. Poniendo en práctica la deliberación, los ciudadanos tratan de buscar el común acuerdo entre

${ }^{83}$ El sentido del término oikia (oỉ ${ }^{2} \alpha$ ) hace referencia al conjunto de elementos que forman la heredad familiar y también tiene el sentido de morada familiar, más que de casa como elemento material de refugio para los seres humanos.

${ }^{84}$ SAlKever, "Women, Soldiers, Citizens: Plato and Aristotle on the Politics of Virility", pp. 178-179.

${ }^{85}$ ARISTÓTELES, Ética a Eudemo 1242a 40-b 1. En este contexto, Aristóteles subraya también la analogía entre oikia (oíkía) y polis ( $\pi$ ó $\lambda \varsigma$ ) como formas de convivencia que diferencian a los hombres de los otros animales: "En efecto, el hombre no es solamente un animal social, sino también familiar, $y$, al revés que los otros animales, no se aparean ocasionalmente hombre y mujer; en un sentido particular, pues, el hombre no es un animal solitario, sino hecho para la asociación con aquellos que son naturalmente sus parientes. Habrá, pues, una cierta comunidad y una cierta justicia, aun cuando no exista la ciudad". Ibid., 1242a 22 y ss.

${ }^{86}$ Martha C. Nussbaum, "Shame, Separateness, and Political Unity: Aristotle's Criticism of Plato", en Amélie O. RORTY (ed.), Essays on Aristotle's Ethics, University of California Press, Berkeley, 1980, p. 395-435; Arlene W. SAXonhouse, "Family, Polity, and Unity: Aristotle on Socrates Community of Wives": Polity, n. ${ }^{\circ} 15$ (1982), pp. 202-219; D. Brendan Nagle, The Household as the Foundation of Aristotle's Polis, Cambridge University Press, Cambridge, 2006.

${ }^{87}$ Uno de los precedentes de la moderna idea de autonomía kantiana está implícita en el ideal de la paideia ( $\left.\pi \alpha \_\delta \varepsilon i ́ \alpha\right)$ aristotélica. Fred D. Miller, “Aristotelian Autonomy”, en Aristide TessiTORE (ed.), Aristotle and Modern Politics. The Persistence of Political Philosophy, University of Notre Dame Press, Notre Dame, Indiana, 2002, pp. 375-402; Nancy SHERman, Making a Necessity of Virtue. Aristotle and Kant on Virtue, Cambridge University Press, Cambridge, 1997, pp. 325-330. 
ellos, que da expresión a su pensar y a su sentir, comunicándoselo unos a otros, para poder desarrollar su vida en común. De este modo, las diferencias potencian el diálogo, el progreso social y la crítica en el marco de la polis ${ }^{88}$.

\subsection{La capacidad del hombre para establecer instituciones políticas}

Una mirada hacia la historia política muestra una realidad innegable: el hombre por naturaleza es un animal político que vive, convive, con otros en una ciudad con el fin de conseguir realizar el ideal de bien vivir, tener una vida excelente. La constitución de la ciudad es la ordenación de las magistraturas que la gobiernan y la distinción del poder. Si la constitución política busca el bien común es correcta; y al contrario, si busca el bien y el provecho de los gobernantes es desviada, corrupta, despótica y perversa. Esto lo afirmó Aristóteles, pero lo han mantenido todos los tratadistas políticos de cualquier época y corriente doctrinal.

La historia demuestra un dato incuestionable: ha habido y habrá una evolución y un cambio continuo de formas políticas, por eso hay que considerar el devenir para poder establecer una teoría política con un fundamento sólido en la realidad histórica. Si la historia enseña esto, la antropología nos muestra que las formas de Estado y de gobierno, las mismas constituciones políticas, son la resultante real de lo más íntimo del ciudadano y su propia vida. La interacción ciudadano/constitución política supone un acto vital porque esta es la realidad, el halo de vida, de una ciudad ${ }^{89}$. Por eso la relación entre ciudadano/constitución política es auténtica, espontánea, válida y configura un estatus incuestionable de la biografía del ciudadano.

Aristóteles apela a la historia, a la evolución política y a unas prácticas políticas que ya no estaban vigentes en su época, pero que todavía vivían en la memoria de sus lectores y oyentes como fuente de información acerca de lo que debía y lo que no debía hacerse en una sociedad para organizar la convivencia ciudadana. La cuestión que se plantea es: ¿por qué los hombres nos organizamos políticamente y no vivimos en la barbarie siendo cada uno un enemigo irreconciliable para el otro? En definitiva, Aristóteles y todos los pensadores han tratado de buscar el fundamento de lo político, de la ciencia política, en unos modelos que, en el pasado, habían mostrado su éxito y su fracaso en una época. Dichos

${ }^{88}$ Stephen S. Salkever, Finding the Mean. Theory and Practice in Aristotelian Political Philosophy, Princeton University Press, Princeton, 1991, pp. 166-167.

${ }^{89}$ ARIstóteles, Política 1295a 40. 
modelos podían y debían servir de pauta para articular las relaciones entre los ciudadanos y para establecer cuál podía ser el régimen político más viable y mejor en cada circunstancia y en cada tiempo.

Aristóteles fue consciente de un hecho que el pensamiento político ha admitido y asimilado: cada régimen político histórico es único e irrepetible. Se pueden establecer categorías y principios generales, pero todo régimen político es cualitativamente diferente a cualquier otro, por eso no se puede admitir la existencia de un proceso regular de cambio, o mutación, sino un ritmo de sustitución y constitución, que no es igual, porque el primero - el cambio o la mutaciónes fatalista mientras el segundo - la sustitución y constitución - plantea la necesidad de aprovechar las experiencias positivas y el aprendizaje que proporciona cada régimen. El uno se encierra en un círculo del que no puede escapar, el otro evoluciona en espiral dirigiéndose hacia un fin. De este modo, se puede hablar de una evolución política - como la biológica - que muestra la existencia de la historia constitucional que se caracteriza por la diversidad de formas políticas y por la convivencia en el tiempo, en distintos lugares, de esta pluralidad. De ahí que el movimiento histórico se pueda decir que es una clase determinada de movimiento que se apoya en una sucesión en la que unos elementos proceden de otros, como unas constituciones proceden de otras y van hacia otras.

Aristóteles detectó en la política la existencia de un movimiento procesual donde lo fundamental es la transmisión de experiencias para todos, y de ahí deducir elementos que nos permitan llegar a desarrollar una teoría política. Cada constitución política muestra una forma única de organizar la convivencia entre los hombres y de ordenar la realidad social. Pero la manera concreta de organización es una opción humana que tiene como fundamento la libertad de los hombres para elegir entre diversas formas políticas, según las posibilidades reales que ofrece cada coyuntura histórica.

Aristóteles no trató en ninguno de sus textos, ni en el caso de la Constitución de Atenas, de construir un relato histórico pormenorizado de las distintas formas políticas que se han dado en las diversas sociedades. Aristóteles utilizó los datos fácticos como los elementos necesarios para comprender la política en su dimensión histórica y teórica y poder llegar a la conclusión siguiente: la política se realiza en la historia, en ella tiene su continuidad, le otorga sentido, le llena de contenido. Así Aristóteles va a explicar tanto la razón de ser de la política como la razón por la cual esta ha evolucionado de una u otra forma; una evolución en la que los individuos son los protagonistas y actores principales. Este hecho atrajo la atención de los pensadores posteriores, y mostró que el hombre en el uso de su libertad y condicionado por la necesidad, podía y debía organizar 
su espacio político de una manera determinada, en coordinación y cooperación con otros seres humanos que eran, igual que él mismo, ciudadanos.

De esta forma se asigna una función fundamental a la historia política y a la reflexión teórica sobre la realidad política, que se podría cifrar en la necesidad de desentrañar qué es lo constante, lo que permanece en el tiempo, y qué es lo contingente, lo que desaparece con unas personas y unas formas políticas cuando estas se extinguen. Para cumplir este propósito, Aristóteles tiene que dar un paso fundamental que ha marcado la reflexión sobre la política en el mundo occidental: mirar hacia la historia para definir los elementos permanentes sometidos a un proceso de evolución y renovación que se puede detectar en la historia política. Para Aristóteles el conocimiento y la experiencia del pasado son necesarios para evitar en el futuro los errores que en él se cometieron.

Al comienzo de la Política, y con el propósito de establecer que el hombre es por naturaleza un zoon politikon, y de ahí que la polis sea una entidad natural que produce la simbiosis vital entre lo político y el ciudadano, Aristóteles ofrece dos explicaciones aparentemente distintas: la primera es una descripción empírica de la génesis de la ciudad, mientras que la segunda es una explicación teórica del hombre como zoon politikon, basada en la posesión del logos.

Por una parte, Aristóteles sugiere que el mejor camino para investigar las cosas es ver cómo se han desarrollado desde el comienzo. Así, subraya que existe una jerarquía en los fines respectivos de la familia, la aldea y la ciudad, que responden a las necesidades crecientes del ser ciudadano, desde las necesidades diarias y primarias a la realización de la vida buena, que es imposible fuera de una comunidad política.

Por otra parte, Aristóteles estudia la peculiaridad de la naturaleza política del hombre. La respuesta parece obvia:

La razón por la que el hombre es un ser social, más que las abejas o que cualquier otra especie de animal gregario, es evidente: la naturaleza no hace nada en vano. El hombre es, por otra parte, el único que tiene un lenguaje inteligible ${ }^{90}$.

Mientras que los otros animales tienen phone que les permite comunicar dolor y placer, restringiendo su experiencia al ámbito de los sentidos, el hombre es capaz de experimentar niveles más profundos de valor en la realidad por medio del logos:

${ }^{90}$ Ibid., 1253a 7-10. 
Ahora bien, el lenguaje inteligible sirve además para manifestar el propio interés así como lo dañino, o lo justo y lo injusto, siendo esto exclusivo del hombre que, así, se diferencia de los demás animales al tener, por ello, el sentido del bien y del mal, el de lo justo y de lo injusto y todo lo demás que le es propio ${ }^{91}$.

Por tanto, de acuerdo con la primera explicación, el término politikon se refiere en sentido propio a una característica del hombre que vive en una comunidad política y que está dotado de logos, mientras que por analogía caracteriza también al resto de animales gregarios. De acuerdo con la segunda interpretación, el uso del término politikon aplicado al resto de animales gregarios no es metafórico, sino que su significado cubre diversos grados de sociabilidad. De ahí que Aristóteles afirme que el hombre es "más" social que las abejas o que cualquier otra especie de animal gregario, estableciendo una continuidad. En un sentido, la definición de Aristóteles es biológica, pero la physis ( $\phi v ́ \sigma ı)$ ) del hombre no es totalmente biológica, sino racional e intelectual.

Sería un grave error entender que la expresión zoon politikon defina la esencia del hombre ${ }^{92}$, pues la naturaleza política del ser humano se deriva de su naturaleza racional. Aristóteles reconoce en varios lugares que, en su estado natural, el ser humano es físicamente más débil que otros animales ${ }^{93}$. De todos los animales, el ser humano es más dependiente que otros de su especie; esto contribuye a su desarrollo mental, cuyo ejemplo más evidente es el logos. Para razonar, para deliberar, el ser humano necesita el $\log o s$, de modo que la naturaleza política del ser humano se fundamenta en el logos, que le permite aprehender lo bueno y lo malo, lo justo y lo injusto. Existe pues una conexión intrínseca entre la naturaleza política del hombre y el hecho de que esté dotado de logos.

La apelación a la historia y al logos, a las prácticas de un pasado que ya no existe, pero que se recuerda y se ha aprendido, como es el caso de las formas políticas que cita en sus libros como fuente de información acerca de lo que debía y no debía hacerse en la política, desempeñó un papel importante en los debates sobre el mejor régimen político, sobre la mejor forma de gobernar. Se trataron de buscar en el pasado argumentos fuertes para intentar la reforma del presente.

91 Ibid., 1253a 14-18.

92 David J. DEPEw, "Humans and Other Political Animals in Aristotle's History of Animals": Phronesis, vol. 40, n. 2 (1995), p. 162 critica, en este sentido, a Heidegger, Arendt y otros que localizan la esencia del ser humano en la naturaleza política del hombre. Para una crítica de otras interpretaciones alemanas similares, inspiradas por Hegel, véase Wolfgang KullmanN, Aristoteles und die moderne Wissenschaft, Steiner, Stuttgart, 1998, pp. 342-343.

93 Aristóteles, De las partes de los animales 687a 23-26. 
Muchos aspectos de la historia política podían y debían servir como modelo para justificar y desarrollar las relaciones entre los hombres y con la comunidad social. Por tanto, el debate sobre el pasado era urgente y necesario en el tiempo histórico en el que vivió Aristóteles, tanto como el debate sobre el presente, y tan importante como la formulación de una teoría política completa que tenía que hundir sus raíces en la experiencia histórica.

Historia y política en Aristóteles están íntimamente unidas, no tanto para conocer de forma erudita un pasado que no existe, sino para comprender en toda su profundidad una dimensión fundamental y natural del modo de ser del hombre: su sociabilidad, es decir, el fin del hombre no sólo tiene sentido en el vivir, sino que se realiza totalmente en el convivir. Vivir y convivir son dos términos de un proceso histórico, biológico y político necesario que se ha dado, se da y se seguirá dando en el tiempo y mientras que los hombres no encuentren una forma de Estado, de gobierno, para organizar la sociedad que sea perfecta, ideal e inmutable. Algo que la historia muestra que es imposible y que, por tanto, estamos lejos de conseguir.

\section{A MOdo de CONCLUSiones}

En este artículo se han subrayado las diferencias existentes entre la concepción de Aristóteles y los autores medievales y modernos que comentaron su obra. La primera diferencia que salta a la vista es que Aristóteles trata de justificar el origen de la comunidad política y cuál entre todas las ensayadas por los hombres es la mejor. No olvidemos que fue testigo del triunfo de la monarquía macedónica y la consolidación del imperio alejandrino, dos formas políticas que no servían de modelo porque eran extra-helénicas. Él apostó por el desarrollo temporal del modo de ser del hombre: primero en la familia es social, llega a ser sociable en la aldea y termina siendo político en la polis. El hilo que une estos tres momentos es la capacidad dialógica del ser humano para tener asuntos en común que convierte el espacio material de una polis en el lugar natural y perfecto, en el más adecuado, no solo para vivir, sino para realizar un ideal superior, el vivir bien.

Este bien vivir alude a un tema central en la vida humana: la consecución de la felicidad. Si el ser humano se juega la felicidad en la organización correcta y adecuada del espacio político y sus instituciones, la estructura que cree tiene que ser capaz de regular y ordenar todas la vidas hacia el fin de la política encauzando la vida, las inquietudes y los proyectos de los ciudadanos, delimitando el camino que deben seguir coordinando sus esfuerzos en un proceso de cooperación que perfecciona y mejora al propio ser humano. Si la armonía social se 
rompe, la vida comunitaria está amenazada de disolución y a punto de extinguirse. Para Aristóteles el modelo había periclitado y cedido su hegemonía al poder concentrado en una persona, pero en la Política no hay resignación, sino ilusión por reverdecer el modelo mejorado y depurado de los errores que le condujo a su colapso, porque para el autor lo importante es que la política se hace con seres humanos que se relacionan porque tienen aptitudes para ello y buscan vías para propiciar la participación activa en los asuntos comunes en una síntesis vital en la que ciudadano y política se encuentran indisolublemente unidos y confundidos.

Los comentaristas que hemos citado abarcan desde el siglo trece al siglo dieciocho, cinco centurias en las que el mundo sufrió todo tipo de convulsiones y cambios. El horizonte político ha cambiado radicalmente y el hombre no interacciona con él. Se ha quebrado la simbiosis entre lo ciudadano y lo político, que se solidifican en dos entidades que seguirán caminos diferentes y paralelos y entre los cuales no habrá contacto ni encuentros. Para los europeos bajomedievales y los europeos del Renacimiento, del Humanismo y de la Ilustración lo político encalla en lo administrativo y en lo individual; lo ciudadano pierde toda proyección al operar sobre la vida y sobre las cosas porque el ciudadano no es para la ciudad, sino para sí mismo, es individuo.

Los autores que hemos visto pretenden con sus versiones del zoon politikon superar el individualismo y ampliar los límites del pensamiento y de la realidad política apoyándose en un pensador genial. Por un lado, tratan de ampliar el campo de lo político proclamando una ciudadanía menos restringida y miope; por otro lado, tratan de encontrar y fundamentar las relaciones humanas en aquello que de más humano encierra el modo de ser del hombre. El fundamento de ambos anhelos resultó ser la realidad primordial de toda proyección tanto social, política como religiosa: el hombre mismo.

¿Cómo es este hombre? ¿Qué es el hombre mismo? A esta pregunta nuestros autores no dan respuesta porque, y ahí radica la diferencia esencial y más profunda con Aristóteles, no consideran al hombre en cuanto sólo tal, en cuanto a lo que de humano posee, que es la esencia del Humanismo, sino que buscan dimensiones parciales de la realidad humana y por eso ora es social, ora político, ora cívico, o todo a la vez sin distinción y sin orden.

Aristóteles marca los límites del hombre: es un ser circunscrito a unas condiciones espaciales y temporales en las que despliega su existencia siendo él mismo y usando su logos común. Sus comentaristas lo lanzan al infinito, a la ausencia de límites, lo convierten en un ser fragmentario y soberbio. Soberbia deriva de superbia, es decir, super-bia pasar al otro lado de la vida, excederse, salirse de un campo propio donde se está seguro y se actúa con libertad. Los 
comentaristas se mueven entre un teocentrismo que aplasta al hombre y un antropocentrismo que desvía a solo lo individual y concreto la existencia humana. La respuesta no está en una u otra postura, porque ambas lo que provocan son las oscilaciones en las versiones del zoon politikon, sino en admitir la limitación humana que surge de nuestro propio modo de ser sujeto a una evolución donde se realizan nuestros proyectos individuales y colectivos.

Aristóteles quería rescatar la tríada armónica, equilibrada e inescindible que

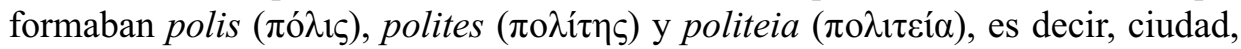
ciudadano y constitución política que determinaban la vida del hombre en su dimensión humana, social y política. Los comentaristas viven, o creen vivir, la época en la que el logos y el hombre mismo condicionan todo el mundo humano.

Los comentaristas de la Política de Aristóteles no podían conseguir ofrecer en latín una traducción exacta del término, porque se encontraban inmersos en otro paradigma político, social, histórico y jurídico que condicionaba su planteamiento. Para todos ellos las relaciones humanas eran binarias, es decir, estaban constituidas por el par cives y civitas, siendo el primero fundamental para crear a la segunda, invirtiendo de esta manera el orden griego, y el sentido de la frase de Aristóteles.

Por otro lado, las versiones no se pueden ordenar ni cronológica, geográfica, filosófica o culturalmente, porque cada autor percibe, dentro de la realidad y de la herencia del derecho romano, la frase de una manera determinada que influye en su traducción y planteamiento.

Finalmente, el logos ha dejado de ser dialógico, y se ha convertido en individual y sirve para determinar, explicar y fundamentar los imperativos que brotan del ser humano como lo político, lo ciudadano, lo religioso y la libertad. Entre estos dos mundos no puede haber comunicación porque los nexos de unión, el logos y el hombre, tienen consideración y forman dos categorías diferentes. Por esta razón no se logra entender ambas palabras y se vierten al latín, la lingua franca del momento, según la posición y la intensidad que se manifiesta en cada época sobre lo político, social o civil. Es un caso más, y no es el único, de incomprensión y deformación de una frase genial de un pensador profundo y original que trató de restaurar en toda su pureza efervescente la conquista inmortal, básica y radical de que el ser humano construye su vida con-viviendo. 